Supplement of Biogeosciences, 14, 4619-4635, 2017

https://doi.org/10.5194/bg-14-4619-2017-supplement

(C) Author(s) 2017. This work is distributed under

the Creative Commons Attribution 3.0 License.

(c) (1)

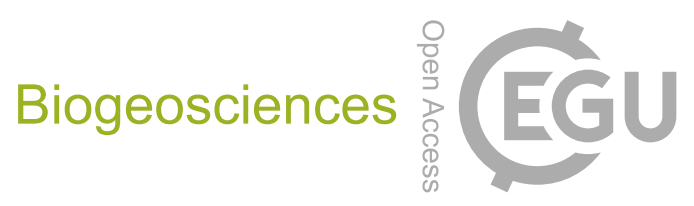

Supplement of

\title{
Expansion of oil palm and other cash crops causes an increase of the land surface temperature in the Jambi province in Indonesia
}

Clifton R. Sabajo et al.

Correspondence to: Clifton R. Sabajo (csabajo@uni-goettingen.de)

The copyright of individual parts of the supplement might differ from the CC BY 3.0 License. 


\section{S1. Surface temperature retrieval from Landsat thermal images}

Surface temperature from Landsat ETM+ is derived in a series in steps using the red (R), near-infrared (NIR) and thermal infrared (TIR) band, and follows the method described by Bastiaanssen et al. (1998a, 1998b) and summarized in table S1.

Table S1.1. Steps in the retrieval of the surface temperature from Landsat 7 TIR band

\begin{tabular}{|c|c|c|c|}
\hline Computation step & Symbol & Unit & Formulation \\
\hline $\begin{array}{l}\text { 1. Conversion of the digital number (DN) of the VIS } \\
\text { and TIR bands to spectral radiance }\end{array}$ & $\mathrm{L}_{\lambda}$ & $\mathrm{W} / \mathrm{m}^{2} / \mathrm{sr} / \mu \mathrm{m}$ & $\mathrm{L}_{\lambda}=\frac{\text { LMAX }- \text { LMIN }}{\text { QCALMAX - QCALMIN }} \times($ DN - QCALMIN $)+$ LMIN \\
\hline $\begin{array}{l}\text { 2. Conversion of spectral radiance bands to reflectance } \\
(\lambda=1,2,3,4,5,6,7)\end{array}$ & $\rho_{\lambda}$ & - & $\rho_{\lambda}=\frac{\pi \times \mathrm{L}_{\lambda}}{E S U N_{\lambda} \times \cos \theta \times d_{r}}$ \\
\hline 3. Normalized Difference Vegetation Index & NDVI & - & $\mathrm{NDVI}=\frac{\rho 4-\rho 3}{\rho 4+\rho 3}$ \\
\hline 4. Soil Adjusted Vegetation Index & SAVI & - & SAVI $=\frac{(1+L)(\rho 4-\rho 3)}{(L+\rho 4+\rho 3)}$ \\
\hline 5. Transformed SAVI to pseudo-LAI ${ }^{\S}$ & SAVI" & - & $\mathrm{SAVI}^{\prime \prime}=\frac{-\ln \left(\frac{0.69-\mathrm{SAVI}}{0.59}\right)}{0.91}$ \\
\hline 6. Narrowband emissivity & $\varepsilon N B$ & - & $\begin{array}{ll}\varepsilon N B=0.97+0.0033 \mathrm{SAVI}^{\prime \prime} & ; \mathrm{SAVI}^{\prime \prime}<3(\mathrm{a}) \\
\varepsilon \mathrm{NB}=0.98 & ; \mathrm{SAVI}^{\prime \prime} \geq 3(\mathrm{~b})\end{array}$ \\
\hline 7. Broadband emissivity & $\varepsilon 0$ & - & $\begin{array}{ll}\varepsilon 0=0.95+0.01 \mathrm{SAVI}^{\prime \prime} & ; \mathrm{SAVI}^{\prime \prime}<3 \text { (a) } \\
\varepsilon 0=0.98 & ; \mathrm{SAVI}^{\prime \prime} \geq 3 \text { (b) }\end{array}$ \\
\hline 8. Atmospheric correction of the thermal radiance band & Rc & $\mathrm{W} / \mathrm{m}^{2} / \mathrm{sr} / \mu \mathrm{m}$ & $\mathrm{Rc}=\frac{\mathrm{L} 6-\mathrm{Rp}}{\tau \mathrm{NB}}-(1-\varepsilon \mathrm{NB}) \mathrm{Rsky}$ \\
\hline 9. Surface temperature calculation & LST & K & $\mathrm{LST}=\frac{\mathrm{k} 2}{\ln \left(\frac{\varepsilon \mathrm{NB} \times \mathrm{k} 1}{\mathrm{Rc}}+1\right)}$ \\
\hline
\end{tabular}


Where:

\begin{tabular}{|c|c|c|}
\hline $\mathrm{DN}$ & the digital number of each pixel of band $\lambda$ & $\mathrm{W} / \mathrm{m}^{2} / \mathrm{sr} / \mu \mathrm{m}$ \\
\hline LMAX & calibration constant specific for each Landsat sensor & $\mathrm{W} / \mathrm{m}^{2} / \mathrm{sr} / \mu \mathrm{m}$ \\
\hline LMIN & (see table $\mathrm{S} 1.2$ ) & \\
\hline QCALMAX & highest and lowest range values for rescaled radiance & $\mathrm{W} / \mathrm{m}^{2} / \mathrm{sr} / \mu \mathrm{m}$ \\
\hline QCALMIN & $\mathrm{DN}$ (see table S1.2) & \\
\hline $\mathrm{ESUN}_{\lambda}$ & $\begin{array}{l}\text { the mean solar exo-atmospheric irradiance for each } \\
\text { band (see table S1.3) }\end{array}$ & $\mathrm{W} / \mathrm{m}^{2} / \mu \mathrm{m}$ \\
\hline$\theta(\theta=9$ & idence angle & angular degrees \\
\hline$\beta$ & on from meta data satellite image & angular degrees \\
\hline $\mathrm{d}_{\mathrm{r}}$ & the relative distance between $\mathrm{e}$ & \\
\hline & $\mathrm{d}_{\mathrm{r}}=1+0.033 \cos \left(\operatorname{DOY} \frac{2 \pi}{365}\right)$ & \\
\hline DOY & the sequential time of the year & \\
\hline & The unit of the angle (DOY $\times \frac{2 \pi}{365}$ ) is in radians. & \\
\hline$\rho_{4}$ & of band $4(\mathrm{NIR}, 750-900 \mathrm{~nm})$ & \\
\hline$\rho_{3}$ & (VIS Red, $630-$ & \\
\hline $\mathrm{L}$ & $\begin{array}{l}\text { adjustment factor to minimize the backscatter effect of } \\
\text { soil background reflectance through the canopy }(0.1)\end{array}$ & \\
\hline$\tau \mathrm{NB}$ & band average atmospheric transmittance & \\
\hline $\mathrm{Rp}$ & $\begin{array}{l}\text { effective bandpass upwelling radiance (or Path } \\
\text { radiance) }\end{array}$ & $\mathrm{W} / \mathrm{m}^{2} / \mathrm{sr} / \mu \mathrm{m}$ \\
\hline Rsky & effective bandpass downwelling radiance & $\mathrm{W} / \mathrm{m}^{2} / \mathrm{sr} / \mu \mathrm{m}$ \\
\hline $1(=$ & sensor constants for converting band 6 to surface & $\mathrm{mW} / \mathrm{cm}^{2} / \mathrm{sr} / \mu \mathrm{m}$ \\
\hline $\mathrm{k} 2(=1282.71)$ & temperature & \\
\hline
\end{tabular}

\#: when using Landsat surface reflectance product, this step is not necessary. §The transformed SAVI is considered here to be equal to the LAI.

References: 4: Huete (1988); 5: Bulcock and Jewitt (2010); 6, 7: Bastiaanssen et al. (1998a, 1998b); 8: Wukelic et al. (1989); Coll et al. (2010).

Table S1.2. LMIN and LMAX values for Landsat 7 ETM+ (Landsat 7 Science User Data Handbook Chap. 11, 2002) in units $\mathrm{W} \mathrm{m}^{-2} \mathrm{sr}^{-1} \mu \mathrm{m}^{-1}$ (after July 1, 2000)

\begin{tabular}{llrrrrrrrr}
\hline & Band number & \multicolumn{1}{c}{$\mathbf{1}$} & \multicolumn{1}{c}{$\mathbf{2}$} & \multicolumn{1}{c}{$\mathbf{3}$} & $\mathbf{4}$ & $\mathbf{5}$ & $\mathbf{6}$ & $\mathbf{7}$ & \multicolumn{1}{c}{$\mathbf{8}$} \\
\hline \multirow{2}{*}{ Low gain } & LMAX & 293,7 & 300,9 & 234,4 & 241,1 & 47,57 & 17,04 & 16,54 & 243,1 \\
& LMIN & $-6,2$ & $-6,4$ & -5 & $-5,1$ & -1 & 0 & $-0,35$ & $-4,7$ \\
& LMAX & 191,6 & 196,5 & 152,9 & 157,4 & 31,06 & 12,65 & 10,8 & 158,3 \\
& LMIN & $-6,2$ & $-6,4$ & -5 & $-5,1$ & -1 & 3,2 & $-0,35$ & $-4,7$ \\
& QCALMAX & 255 & 255 & 255 & 255 & 255 & 255 & 255 & 255 \\
& QCALMIN & 1 & 1 & 1 & 1 & 1 & 1 & 1 & 1 \\
\hline
\end{tabular}

Table S1.3. Mean solar exo-atmospheric irradiance (ESUN $\lambda$ ) for Landsat 7 ETM + (Landsat 7 Science User Data Handbook, Chapter 11, 2002). Units are in $\mathrm{W} / \mathrm{m}^{2} / \mu \mathrm{m}$.

\begin{tabular}{ccccccccc}
\hline & Band 1 & Band 2 & Band 3 & Band 4 & Band 5 & Band 61 & Band 62 & Band 7 \\
\hline Landsat 7 & 1969 & 1840 & 1551 & 1044 & 225.7 & 1 & 1 & 82.07 \\
\hline
\end{tabular}




\section{S2. Atmospheric correction of the thermal band}

For the atmospheric correction of the thermal radiance, the correction parameters $\tau$, Rp and Rsky are derived from NASA's online atmospheric correction calculator (Barsi et al., 2003, 2005) which requires the following input: latitude and longitude, elevation, air temperature, surface pressure and relative air humidity. This Web-based ACT has been developed for TM and ETM+ thermal data (Barsi et al., 2005; Coll et al., 2010). It uses atmospheric profiles from the National Centers for Environmental Prediction (NCEP) interpolated to a particular location, date and time, and the MODTRAN-4 code to calculate the atmospheric-correction parameters for the bandpass of either the TM or ETM+ thermal band for a given date and site (Coll et al., 2010). The output of the online atmospheric parameter calculator is: band average atmospheric transmission $(\tau)$, effective bandpass upwelling radiance $(\mathrm{Rp})$ and the effective bandpass downwelling radiance (Rsky). The calculated atmospheric parameters can be applied to a given scene to retrieve the surface temperature for the area of interest. The thermal band (L6) is corrected for atmospheric effects after Wukelic et al. (1989) and Coll et al. (2010) as:

$$
\mathrm{Rc}=\frac{\mathrm{L} 6-\mathrm{Rp}}{\tau}-(1-\varepsilon \mathrm{NB}) \mathrm{Rsky}
$$

The input data required for the atmospheric calculator and the output parameters required for atmospheric correction and applied to the selected Landsat satellite image are summarized in table S2.1.

Table S2.1. Input and output parameters for/from NASA's online atmospheric correction parameter calculator applied to two satellite images of the study area. Results in this study were based on the satellite image acquired on 2013-06-19.

\begin{tabular}{llr}
\hline Location & Date (yyyy-mm-dd): & $\mathbf{2 0 1 3 - 0 6 - 1 9}$ \\
\hline Input & Lat & -1.966 \\
& Lon & 102.601 \\
& GMT Time: & $3: 13$ \\
\hline Input surface & Surface altitude $(\mathrm{km}):$ & 0.046 \\
conditions & Surface pressure (mb): & 1002.90 \\
& Surface air temperature (C): & 28.35 \\
& Surface relative humidity (\%): & 50.90 \\
\hline Output & Band average atmospheric transmission: & 0.67 \\
summary & Effective bandpass upwelling radiance: & 2.68 \\
& Effective bandpass downwelling radiance: & 4.25 \\
\hline Band average atmospheric transmission $=\tau$, effective bandpass upwelling radiance $=$ Rp
\end{tabular}

$\left(\mathrm{W} / \mathrm{m}^{2} / \mathrm{sr} / \mu \mathrm{m}\right)$, effective bandpass downwelling radiance $=$ Rsky $\left(\mathrm{W} / \mathrm{m}^{2} / \mathrm{sr} / \mu \mathrm{m}\right)$. 
Steps in deriving ET with the SEBAL

1. Net radiation $\left(\mathrm{Rn}, \mathrm{W} / \mathrm{m}^{2}\right)$ is calculated as:

$\mathrm{Rn}=(1-\alpha) \mathrm{S}_{\mathrm{d}} \downarrow+\varepsilon_{\mathrm{a}} \sigma \mathrm{T}_{\mathrm{a}}^{4}-\left(1-\varepsilon_{0}\right) \varepsilon_{\mathrm{a}} \sigma \mathrm{T}_{\mathrm{a}}^{4}-\varepsilon_{0} \sigma \mathrm{LST}^{4}$

$\mathrm{Rn}$ is the net radiation $\left(\mathrm{W} / \mathrm{m}^{2}\right)$;

$\mathrm{S}_{\mathrm{d} \downarrow} \downarrow$ is the incoming shortwave solar radiation (in $\mathrm{W} / \mathrm{m}^{2}$ ) at the surface;

$\alpha$ is the surface albedo (-)

$\varepsilon_{0}$ : the surface emissivity (-), derived from the NDVI and is described in table S1.

$\varepsilon_{\mathrm{a}}$ : the atmospheric emissivity (-), estimated with:

$\left.\varepsilon \mathrm{a}=1-0.26 \times \exp \left(-7.77 \times 10^{-4}\right) \times(273.15-\mathrm{Ta})^{2}\right)$

$\sigma:$ Stephan-Boltzmann constant $\left(5.67 \times 10^{-8} \mathrm{~W} / \mathrm{m}^{2} / \mathrm{K}^{4}\right)$;

LST: the surface temperature $(\mathrm{K})$ derived from Landsat;

$\mathrm{T}_{\mathrm{a}}$ : is the (near surface) air temperature / sky temperature $(\mathrm{K})$.

2. Soil heat flux $\left(\mathrm{G}, \mathrm{W} / \mathrm{m}^{2}\right)$ is calculated as:

$\mathrm{G}=\mathrm{Rn} \times \frac{\mathrm{LST}-273.15}{\alpha} \times\left(0.0038 \alpha+0.0074 \alpha^{2}\right) \times\left(1-0.98 \mathrm{NDVI}^{4}\right)$

$\mathrm{G}$ is the ground heat flux $\left(\mathrm{W} / \mathrm{m}^{2}\right)$;

$\mathrm{Rn}$ is the net radiation $\left(\mathrm{W} / \mathrm{m}^{2}\right)$;

LST: the surface temperature $(\mathrm{K})$ derived from Landsat;

$\alpha$ is the surface albedo (-)

3. Sensible heat flux $\left(\mathrm{H}, \mathrm{W} / \mathrm{m}^{2}\right)$ is calculated in a series of steps as:

a. $\mathrm{Z}_{0 \mathrm{~m}}$ (the particular momentum roughness length for each pixel) is derived from an empirical relation between $\mathrm{z}_{0} \mathrm{~m}$ and NDVI and albedo as

$z_{0 m}=e^{\left(a \times \frac{N D V I}{\alpha}\right)+b}$

coefficients $a$ and $b$ are derived from the linear relation between:

$\ln \mathrm{z}_{0 \mathrm{~m}} \sim \mathrm{a} \times \frac{N D V I}{\alpha}+\mathrm{b}$ 
From figure $\mathrm{S} 3.1 \mathrm{~b}$ we derived $a$ and $b$ as:

$\mathrm{a}=0.24$

$\mathrm{b}=-2.29$

b. friction velocity $\left(\mathrm{u}^{*}, \mathrm{~m} / \mathrm{s}\right)$ at weather station $\left(\mathrm{u}_{200}, \mathrm{~m} / \mathrm{s}\right)$ is derived as:

$$
u^{*}=\frac{k \times u_{z}}{\ln \left(\frac{z}{z_{0 m}}\right)}
$$

c. the wind speed $200 \mathrm{~m}$ above the weather station $\left(\mathrm{u}_{200}, \mathrm{~m} / \mathrm{s}\right)$ is derived as:

$u_{200}=u^{*} \frac{\ln \left(\frac{200}{z_{0 m}}\right)}{k}$

$\mathrm{k}=$ von Karman's constant $=0.41$

$\mathrm{Z}_{0 \mathrm{~m}}=$ as calculated with Eq. $\mathrm{S} 4$

c. The aerodynamic resistance to heat transport $\mathrm{r}_{\mathrm{ah}}(\mathrm{s} / \mathrm{m})$ is calculated as:

$r_{a h}=\frac{\ln \left(\frac{z_{2}}{z_{1}}\right)}{u^{*} \times k}$

d. the near surface temperature difference (dT) for each pixel is defined as:

$\mathrm{dT}=\mathrm{b}+\mathrm{a} \operatorname{LST}$

$a$ and $b$ are correlation coefficients which are derived by:

i. selecting hot and cold pixels (a.k.a. anchor pixels) in the LST image

ii. using an excel sheet the coefficients $a$ and $b$ are derived from several iterations

e. finally sensible heat $(\mathrm{H})$ is estimated as:

$\mathrm{H}=\rho \times \mathrm{Cp} \frac{a L S T+b}{\mathrm{r}_{\mathrm{ah}}}$

$r_{a h}=$ aerodynamic resistance to heat transport $r_{a h}(\mathrm{~s} / \mathrm{m})$

$\rho=1.16 \mathrm{~kg} / \mathrm{m}^{3}$ (air density)

$\mathrm{Cp}=1004 \mathrm{~J} / \mathrm{kg} / \mathrm{K}$ (air specific heat) 

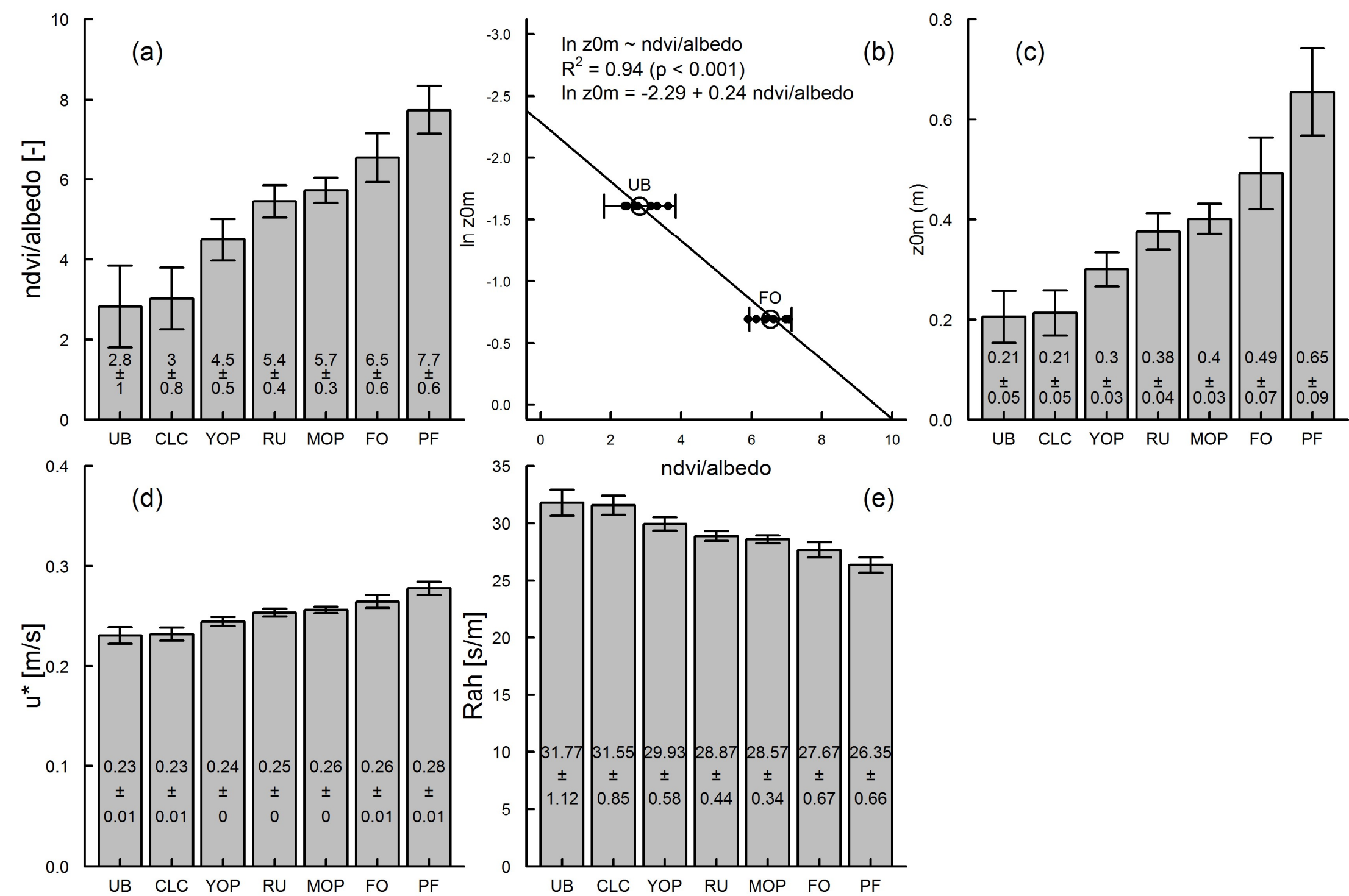

Fig. S3.1 Analysis of the steps involved in deriving the input for deriving ET from Landsat images with SEBAL. 
We calculated $u^{*}$ and $r_{a h}$ for a young and mature oil palm plantation (table S3.1). These were calculated from meteorological measurement on these locations. Because the satellite image was acquired outside the time period in which meteorological measurements were made, we selected dates and times that had similar conditions on the day the image was acquired. We used incoming shortwave radiation as a main criteria $\left(>690 \mathrm{Wm}^{-2}\right.$ and $<720 \mathrm{Wm}^{-2}$, between 10.00 and 11:00 am local time). $u^{*}$ and $r_{a h}$ derived from the satellite image show a certain level of agreement with the $u^{*}$ and $r_{a h}$ calculated from meteorological data.

4. Latent heat flux $\left(\mathrm{LE}, \mathrm{W} / \mathrm{m}^{2}\right)$ is estimated as residual from Net radiation, Ground heat and sensible heat flux as:

$\mathrm{LE}=\mathrm{Rn}-\mathrm{G}-\mathrm{H}$

5. Instantaneous evapotranspiration $(\mathrm{ET}, \mathrm{mm} / \mathrm{hr})$ for each pixel is estimated from LE as:

$E T_{\text {inst }}=3600 \frac{L E}{\lambda}$

3600 is the time conversion from seconds to hours

$\lambda=$ latent heat of vaporization $\left(2.43 \times 10^{6} \mathrm{~J} / \mathrm{kg}\right)$

We tested different combinations of 5 hot and 5 cold pixels, that could serve as anchor pixels, and then compared the effects of anchor pixel selection on the ET output. Our comparison showed that the anchor pixels we selected showed an overall effect on the magnitude of ET of less than $10 \%$ and had no effect on the ranking of the ET by land use type (Fig. S3.2).

We calculated $L E$ and $H$ for a young and mature oil palm plantation (table S3.1). These were calculated from flux measurements on these locations. Because the satellite image was acquired outside the time period in which meteorological measurements were made, we selected dates and times that had similar conditions on the day the image was acquired. $L E$ and $H$ derived from the satellite image show some agreement with the $L E$ and $H$ calculated from meteorological data.

The technical description can be found in Bastiaanssen et al. (1998a, 1998b).

Table S3.1. $u^{*}, r_{a h}, \mathrm{LE}$ and $\mathrm{H}$ measured at a young and mature oil palm plantation

\begin{tabular}{l|rr|rr}
\hline & \multicolumn{2}{|c|}{ Young Oil Palm Plantation (YOP) } & \multicolumn{2}{c}{ Mature oil Palm Plantation (MOP) } \\
\hline & \multicolumn{1}{|c|}{ Lower limit } & \multicolumn{1}{c}{ Upper limit } & \multicolumn{1}{c}{ Lower limit } & \multicolumn{1}{c}{ Upper limit } \\
\hline $\boldsymbol{u}^{\star}(\mathbf{m} / \mathbf{s})$ & $0.40 \pm 0.15$ & $0.47 \pm 0.18$ & $0.12 \pm 0.02$ & $0.37 \pm 0.11$ \\
$\mathbf{r}_{\text {ah }}(\mathbf{s} / \mathbf{m})$ & $24.14 \pm 11.80$ & $26.92 \pm 12.17$ & $22.93 \pm 5.20$ & $54.97 \pm 7.13$ \\
$\mathbf{L E}\left(\mathbf{W} / \mathbf{m}^{2}\right)$ & $215.77 \pm 61.05$ & $226.22 \pm 68.29$ & $413.67 \pm 109.54$ & $441.00 \pm 109.76$ \\
$\mathbf{H}\left(\mathbf{W} / \mathbf{m}^{2}\right)$ & $138.34 \pm 50.85$ & $140.57 \pm 51.32$ & $90.11 \pm 32.64$ & $97.25 \pm 33.56$ \\
\hline
\end{tabular}

$\S$ The table shows 2 values for $u^{*}, \mathrm{r}_{\mathrm{ah}}, \mathrm{LE}$ and $\mathrm{H}$. These values were calculated for the lower $\left(>690 \mathrm{~W} / \mathrm{m}^{2}\right)$ and upper $\left(<720 \mathrm{~W} / \mathrm{m}^{2}\right)$ limit of incoming solar radiation we selected to match conditions on the day the satellite image was acquired. 

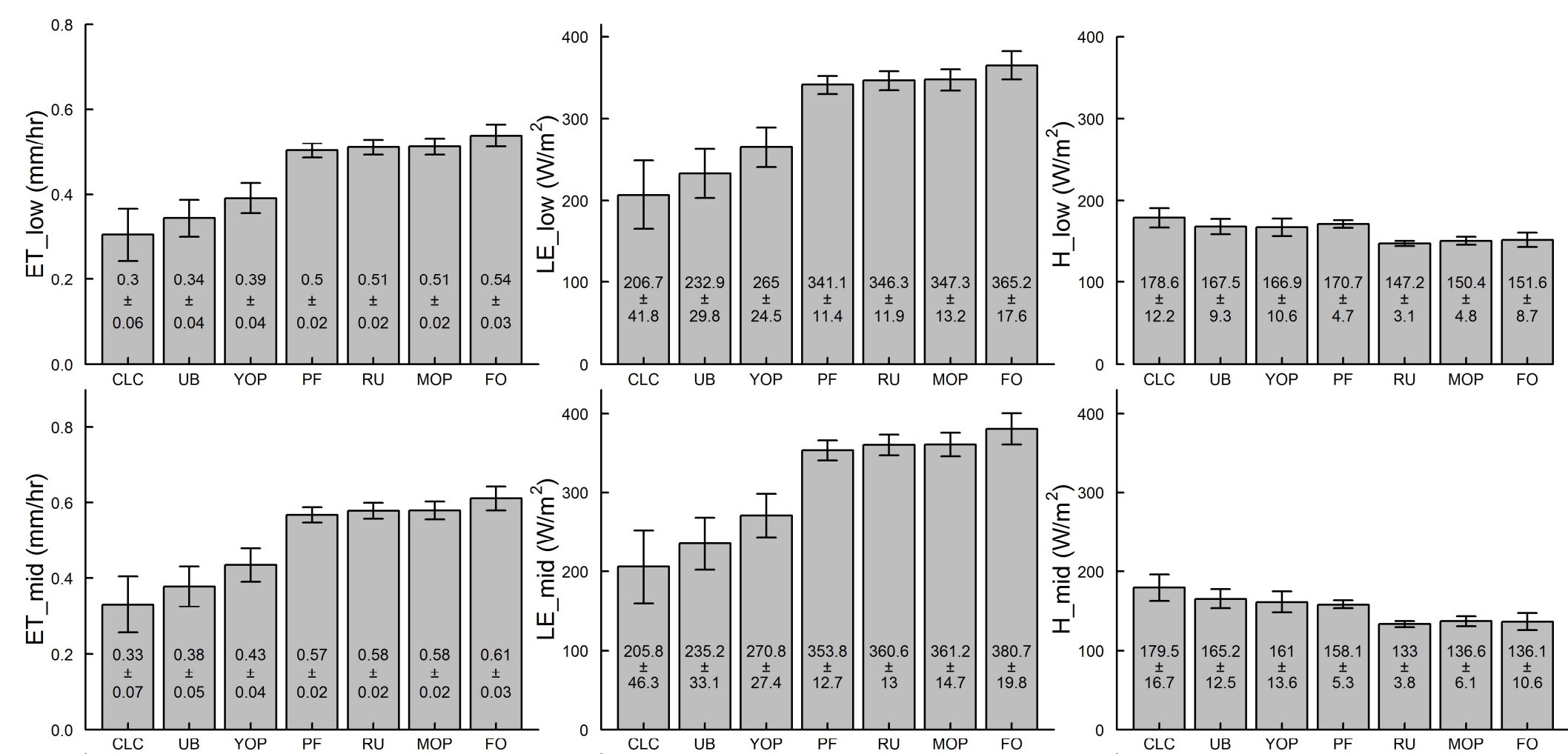

400
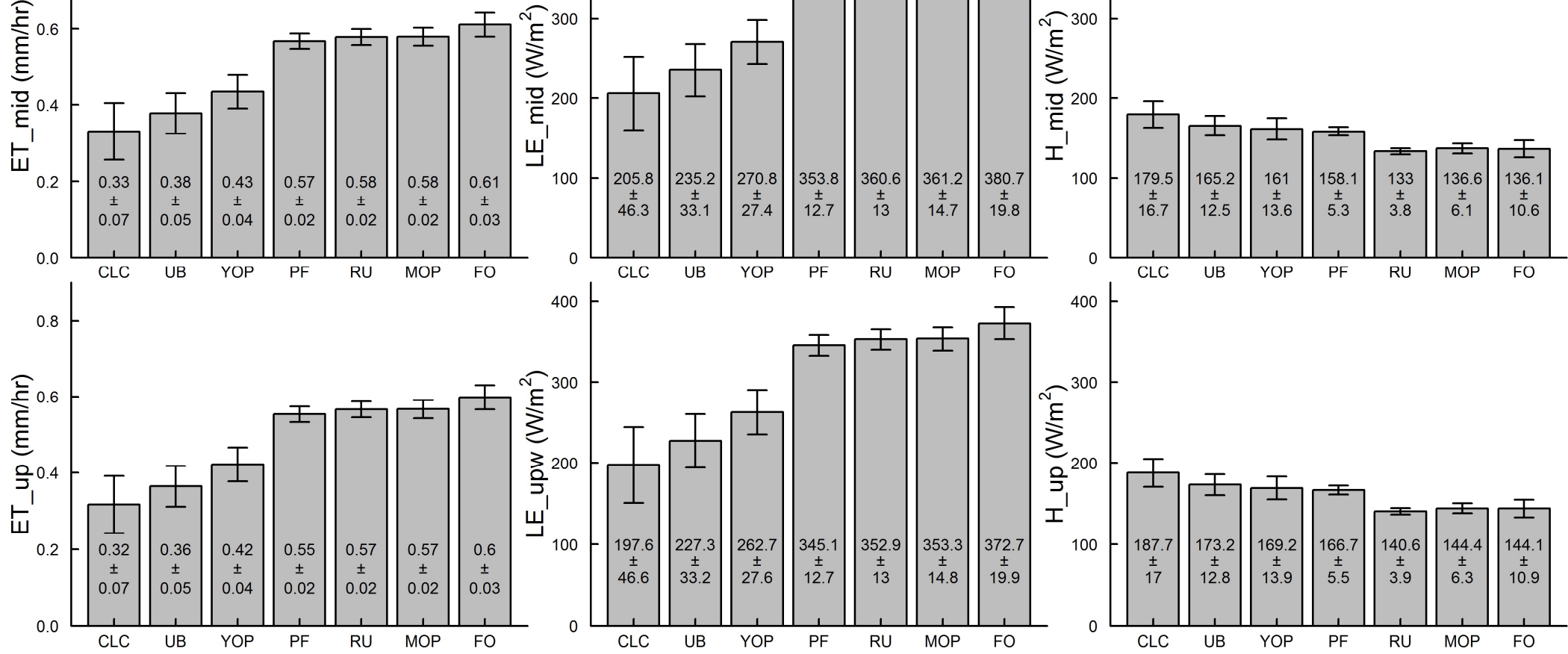

Fig. S3.2 ET, LE and H derived with SEBAL. 

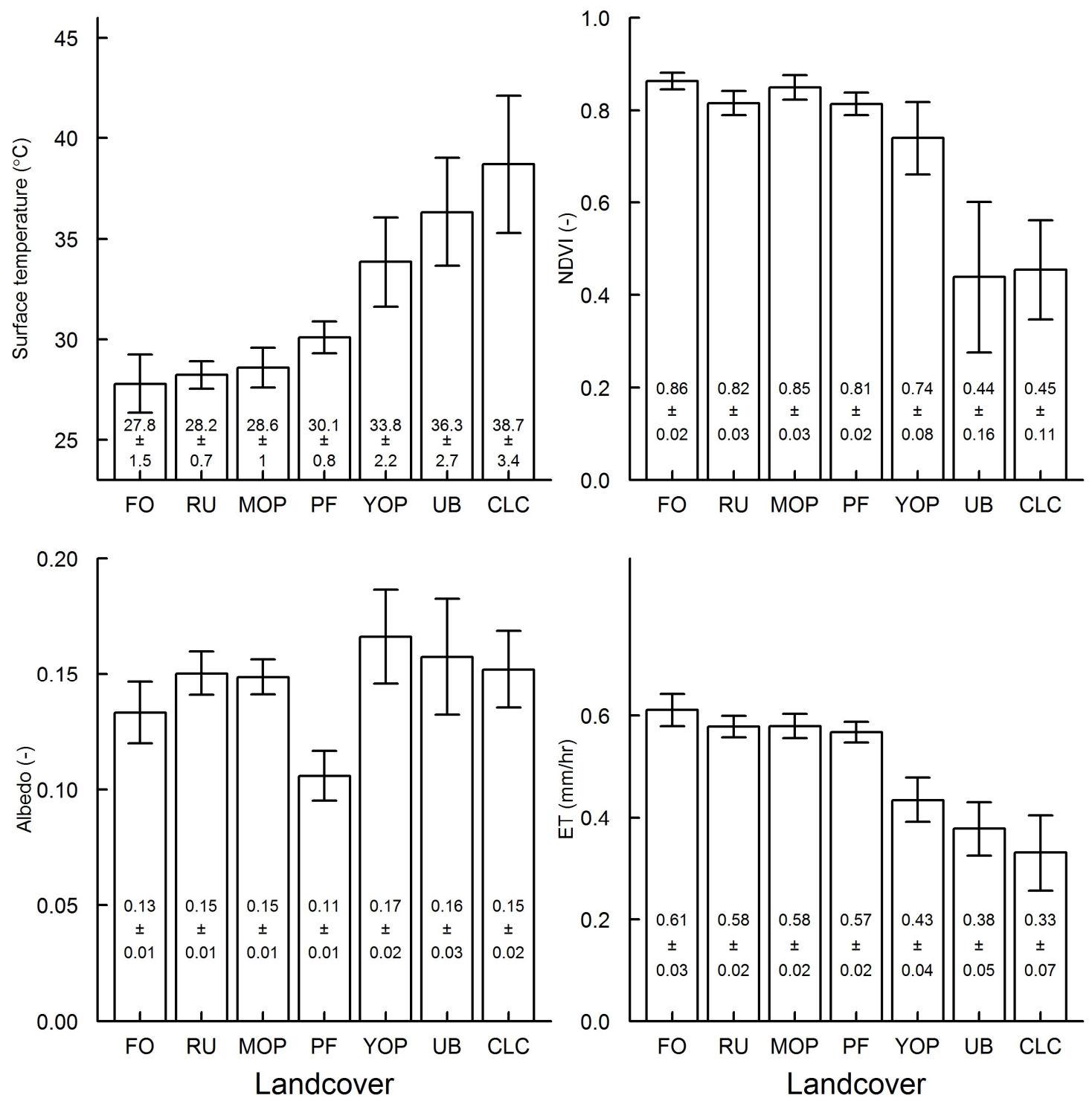

Fig. S4.1 Mean LST, NDVI, Albedo and NDVI extracted from Landsat LST images for 7 land cover types. The values were extracted from small plots that could only be used for Landsat images. 

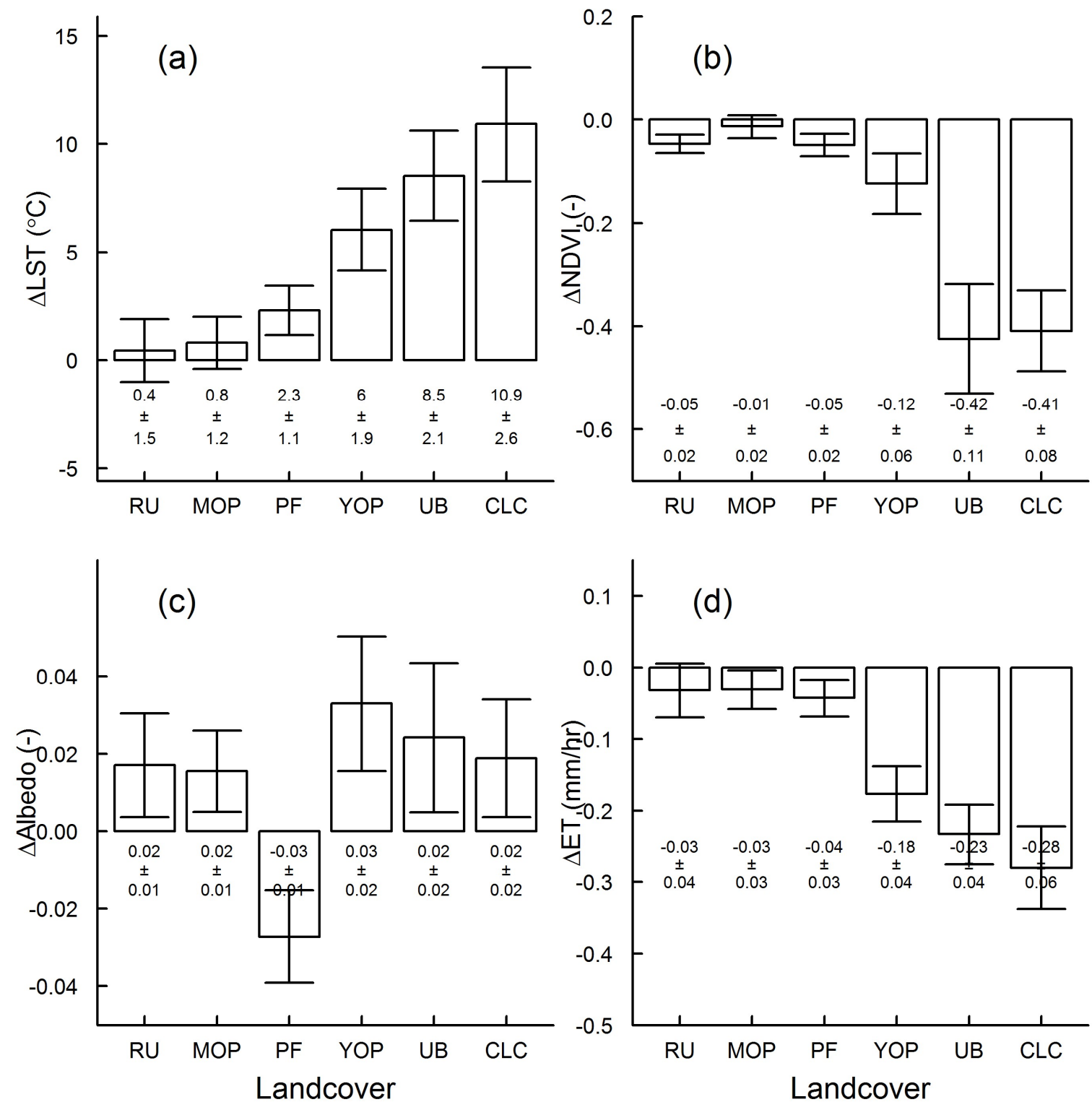

Fig. S5.1 Differences (mean \pm SD) in surface temperature ( $\triangle \mathrm{LST})$, normalized difference vegetation index $(\triangle \mathrm{NDVI})$, Albedo $(\triangle \mathrm{Albedo})$ and Evapotranspiration $(\Delta \mathrm{ET})$ between other land covers (RU, MOP, PF, YOP, UB and CLC) and forest (FO) in the Jambi province, derived from the Landsat LST image acquired on 19 June 2013 at 10:13 am local time.

The standard deviation of 2 means is calculated as the 'pooled standard deviation':

$$
s d=\sqrt{\frac{(n 1-1) s d 1^{2}+(n 2-1) s d 2^{2}}{n 1+n 2-2}}
$$

n1: sample size population 1 (here: the number of pixels of land cover class Forest, FO)

n2: sample size population 2 (here: the number of pixels of land cover class $i(i=\mathrm{RU}, \mathrm{MOP}$, PF, YOP, CLC, UB)

sd1: standard deviation of the mean of the first population (here: Forest, FO)

$\mathrm{sd} 2$ : standard deviation of the mean of the second population $i$ ( $i=\mathrm{RU}, \mathrm{MOP}, \mathrm{PF}, \mathrm{YOP}, \mathrm{CLC}$, UB) 
S6. Statistical analysis

Table S6.1 ANOVA statistics

\begin{tabular}{llrrrrr}
\hline & & Df & Sum Sq. & Mean Sq. & F value & Pr( $>$ F) \\
\hline L6 & Group & 6 & 5033 & 839 & 24073 & $* * *$ \\
& Residuals & 41583 & 1449 & 0 & & \\
Rc & Group & 6 & 13444 & 2241 & 25597 & $* * *$ \\
& Residuals & 41583 & 3640 & 0 & & \\
LST & Group & 6 & 657323 & 109554 & 26240 & $* * *$ \\
& Residuals & 41583 & 173612 & 4 & & \\
Albedo & Group & 6 & 17.0 & 2.84 & 11492 & $* * *$ \\
& Residuals & 41583 & 10.3 & 0.00 & & \\
NDVI & Group & 6 & 1197 & 200 & 32402 & $* * *$ \\
& Residuals & 41583 & 256 & 0 & & \\
ET & Group & 6 & 464 & 77.3 & 41141 & $* * *$ \\
& Residuals & 41583 & 78 & 0.0 & & \\
\hline
\end{tabular}

$* * *: p=2 \times 10^{-16}$ 
Table S6.2 Post-hoc Tukey HSD test statistics

\begin{tabular}{|c|c|c|c|c|c|c|c|}
\hline \multirow[b]{2}{*}{ L6 } & & \multicolumn{6}{|c|}{ Land cover } \\
\hline & & UB & FO & MOP & YOP & PF & CLC \\
\hline & FO & 0.00000 & & & & & \\
\hline & MOP & 0.00000 & 0.00000 & & & & \\
\hline & YOP & 0.00000 & 0.00000 & 0.00000 & & & \\
\hline & $\mathbf{P F}$ & 0.00000 & 0.00000 & 0.00000 & 0.00000 & & \\
\hline & CLC & 0.00000 & 0.00000 & 0.00000 & 0.00000 & 0.00000 & \\
\hline & $\mathbf{R U}$ & 0.00000 & 0.79912 & 0.90144 & 0.00000 & 0.00000 & 0.00000 \\
\hline \multirow[t]{7}{*}{ Re } & & UB & FO & MOP & YOP & PF & CLC \\
\hline & FO & 0.00000 & & & & & \\
\hline & MOP & 0.00000 & 0.00000 & & & & \\
\hline & YOP & 0.00000 & 0.00000 & 0.00000 & & & \\
\hline & PF & 0.00000 & 0.00000 & 0.00000 & 0.00000 & & \\
\hline & CLC & 0.00000 & 0.00000 & 0.00000 & 0.00000 & 0.00000 & \\
\hline & RU & 0.00000 & 0.83540 & 0.91619 & 0.00000 & 0.00000 & 0.00000 \\
\hline \multirow[t]{7}{*}{ LST } & & UB & FO & MOP & YOP & PF & CLC \\
\hline & FO & 0.00000 & & & & & \\
\hline & MOP & 0.00000 & 0.00000 & & & & \\
\hline & YOP & 0.00000 & 0.00000 & 0.00000 & & & \\
\hline & PF & 0.00000 & 0.00000 & 0.00000 & 0.00000 & & \\
\hline & CLC & 0.00000 & 0.00000 & 0.00000 & 0.00000 & 0.00000 & \\
\hline & $\mathbf{R U}$ & 0.00000 & 0.78391 & 0.89703 & 0.00000 & 0.00000 & 0.00000 \\
\hline \multirow[t]{7}{*}{ NDVI } & & UB & FO & MOP & YOP & PF & CLC \\
\hline & FO & 0.00000 & & & & & \\
\hline & MOP & 0.00000 & 0.00000 & & & & \\
\hline & YOP & 0.00000 & 0.00000 & 0.00000 & & & \\
\hline & PF & 0.00000 & 0.00000 & 0.00000 & 0.00000 & & \\
\hline & CLC & 0.00000 & 0.00000 & 0.00000 & 0.00000 & 0.00000 & \\
\hline & $\mathbf{R U}$ & 0.00000 & 0.00099 & 0.05903 & 0.00000 & 1.00000 & 0.00000 \\
\hline \multirow[t]{7}{*}{ Albedo } & & UB & FO & MOP & YOP & PF & CLC \\
\hline & FO & 0.00000 & & & & & \\
\hline & MOP & 0.00000 & 0.00000 & & & & \\
\hline & YOP & 0.00000 & 0.00000 & 0.00000 & & & \\
\hline & PF & 0.00000 & 0.00000 & 0.00000 & 0.00000 & & \\
\hline & CLC & 0.00000 & 0.00000 & 0.00000 & 0.00000 & 0.00000 & \\
\hline & RU & 0.04009 & 0.00000 & 0.99443 & 0.00000 & 0.00000 & 0.99009 \\
\hline \multirow[t]{7}{*}{ ET } & & UB & FO & MOP & YOP & PF & CLC \\
\hline & FO & 0.00000 & & & & & \\
\hline & MOP & 0.00000 & 0.00000 & & & & \\
\hline & YOP & 0.00000 & 0.00000 & 0.00000 & & & \\
\hline & PF & 0.00000 & 0.00000 & 0.00000 & 0.00000 & & \\
\hline & CLC & 0.00000 & 0.00000 & 0.00000 & 0.00000 & 0.00000 & \\
\hline & RU & 0.00000 & 0.00000 & 1.00000 & 0.00000 & 0.62621 & 0.00000 \\
\hline
\end{tabular}


Table S6.3 The relation LST-Albedo-NDVI-ET separated by land cover type.

\begin{tabular}{|c|c|c|c|c|c|c|}
\hline & \multicolumn{3}{|c|}{ Rc } & \multicolumn{3}{|c|}{ LST } \\
\hline FO & $\alpha$ & NDVI & ET & $\alpha$ & NDVI & ET \\
\hline$\rho$ & -0.31 & -0.48 & -0.96 & -0.30 & -0.48 & -0.96 \\
\hline $\mathbf{R}^{2}$ & 0.09 & 0.06 & 0.96 & 0.09 & 0.06 & 0.97 \\
\hline $\boldsymbol{\beta}$ & -4.67 & 1.42 & -6.36 & -33.86 & 10.38 & -46.43 \\
\hline Stand. $\beta$ & -0.31 & 0.13 & -1.01 & -0.31 & 0.126 & -1.01 \\
\hline Modelfit $\left(\mathbf{R}^{2}\right)$ & 0.99 & & & 0.99 & & \\
\hline $\mathbf{R U}$ & $\alpha$ & NDVI & ET & $\boldsymbol{\alpha}$ & NDVI & ET \\
\hline$\rho$ & 0.20 & -0.48 & -0.89 & 0.20 & -0.48 & -0.89 \\
\hline $\mathbf{R}^{2}$ & 0.12 & 0.18 & 1.29 & 0.12 & 0.18 & 1.29 \\
\hline $\boldsymbol{\beta}$ & -5.59 & 1.34 & -6.50 & -40.89 & 9.74 & -47.47 \\
\hline Stand. $\beta$ & -0.57 & 0.37 & -1.45 & -0.57 & 0.37 & -1.45 \\
\hline Modelfit $\left(\mathbf{R}^{2}\right)$ & 0.99 & & & 0.99 & & \\
\hline PF & $\alpha$ & NDVI & ET & $\alpha$ & NDVI & ET \\
\hline$\rho$ & 0.26 & -0.30 & -0.98 & 0.26 & -0.30 & -0.98 \\
\hline $\mathbf{R}^{2}$ & 0.07 & 0.06 & 1.12 & 0.07 & 0.06 & 1.12 \\
\hline $\boldsymbol{\beta}$ & -2.87 & 0.87 & -6.22 & -20.74 & 6.26 & -44.55 \\
\hline Stand. $\beta$ & -0.28 & 0.19 & -1.15 & -0.28 & 0.19 & -1.146 \\
\hline Modelfit $\left(\mathbf{R}^{2}\right)$ & 0.99 & & & 0.99 & & \\
\hline MOP & $\alpha$ & NDVI & ET & $\alpha$ & NDVI & ET \\
\hline$\rho$ & -0.15 & -0.41 & -0.95 & -0.15 & -0.41 & -0.95 \\
\hline $\mathbf{R}^{2}$ & 0.05 & 0.11 & 1.07 & 0.05 & 0.11 & 1.07 \\
\hline $\boldsymbol{\beta}$ & -5.32 & 1.42 & -6.51 & -38.50 & 10.36 & -47.26 \\
\hline Stand. $\beta$ & -0.30 & 0.27 & -1.12 & -0.302 & 0.27 & -1.13 \\
\hline Modelfit $\left(\mathbf{R}^{2}\right)$ & 0.99 & & & 0.99 & & \\
\hline YOP & $\boldsymbol{\alpha}$ & NDVI & ET & $\alpha$ & NDVI & ET \\
\hline$\rho$ & -0.71 & -0.58 & -0.93 & -0.72 & -0.58 & -0.92 \\
\hline $\mathbf{R}^{2}$ & 0.25 & 0.12 & 0.87 & 0.26 & 0.12 & 0.86 \\
\hline $\boldsymbol{\beta}$ & -5.55 & 0.85 & -6.79 & -39.11 & 6.06 & -47.52 \\
\hline Stand. $\beta$ & -0.36 & 0.21 & -0.93 & -0.36 & 0.21 & -0.94 \\
\hline Modelfit $\left(\mathbf{R}^{2}\right)$ & 0.99 & & & 0.99 & & \\
\hline UB & $\alpha$ & NDVI & ET & $\boldsymbol{\alpha}$ & NDVI & ET \\
\hline$\rho$ & -0.44 & -0.72 & -0.89 & -0.44 & -0.72 & -0.89 \\
\hline $\mathbf{R}^{2}$ & 0.20 & 0.02 & 0.77 & 0.19 & 0.02 & 0.78 \\
\hline $\boldsymbol{\beta}$ & -6.95 & -0.08 & -6.40 & -47.69 & -0.51 & -44.22 \\
\hline Stand. $\beta$ & -0.45 & -0.03 & -0.87 & -0.45 & -0.03 & -0.87 \\
\hline Modelfit $\left(\mathbf{R}^{2}\right)$ & 0.99 & & & 0.99 & & \\
\hline CLC & $\alpha$ & NDVI & ET & $\alpha$ & NDVI & ET \\
\hline$\rho$ & -0.13 & -0.68 & -0.98 & -0.13 & -0.68 & -0.98 \\
\hline $\mathbf{R}^{2}$ & 0.03 & 0.05 & 1.02 & 0.03 & 0.04 & 1.01 \\
\hline $\boldsymbol{\beta}$ & -6.21 & 0.35 & -7.10 & -42.87 & 1.97 & -47.66 \\
\hline Stand. $\beta$ & -0.20 & 0.07 & -1.05 & -0.21 & 0.06 & -1.04 \\
\hline Modelfit $\left(\mathbf{R}^{2}\right)$ & 0.99 & & & 0.99 & & \\
\hline
\end{tabular}

All metrics were highly significant $\left(\mathrm{p}=2 \times 10^{-16}\right)$.

Abbreviations: $\mathrm{FO}=$ Forest, $\mathrm{RU}=$ Rubber, $\mathrm{PF}=$ Acacia Plantation Forest, $\mathrm{MOP}=$ Mature Oil Palm, YOP $=$ Young Oil palm, $\mathrm{CLC}=$ Clear cut land, $\mathrm{UB}=$ Urban Areas 


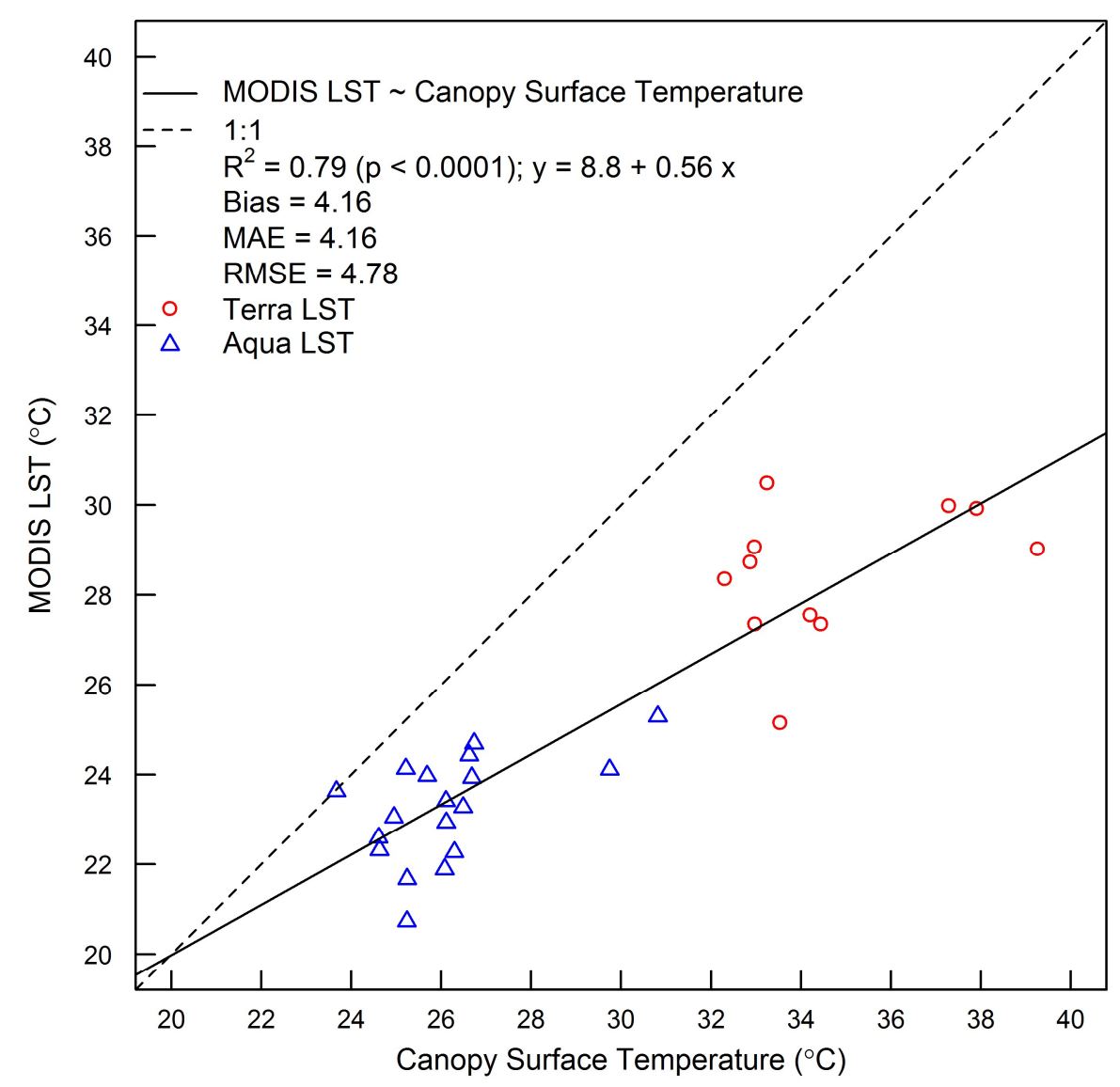

Fig. S7.1 MODIS LST compared to in situ measured canopy surface temperature.

Canopy surface temperature was measured above a homogeneous mature oil palm plantation (12 years old). MODIS LST during 1 1/2 year (mid 2014 - end 2015) was extracted from the pixel covering the location where the in situ canopy surface temperature was measured. LST from MODIS on the Terra and Aqua platform were used: Aqua LST in our comparison were measured in the evening hours (around 22:30, local time), Terra LST were measured during morning hours (10:30 am, local time).

Both in situ and MODIS observations are consistent, i.e. the morning temperatures (10:30 am local time vs Terra LST) were warmer than the evening temperatures $(10: 30 \mathrm{pm}$ local time vs Aqua LST). Differences between the two sources are caused by the comparison of point measurements with pixel values, differences in spatial resolution, differences in soil contribution to the LST estimate, distance in LST measurements and particularly differences in emissivity used for temperature correction. The thermal infrared sensor measuring the surface canopy temperature of the oil palm plantation had fixed default values. MODIS emissivity is derived from 3 thermal bands and adjusted accordingly for every measurement. 
S8. Comparison of MODIS Air temperature with locally measured air temperature

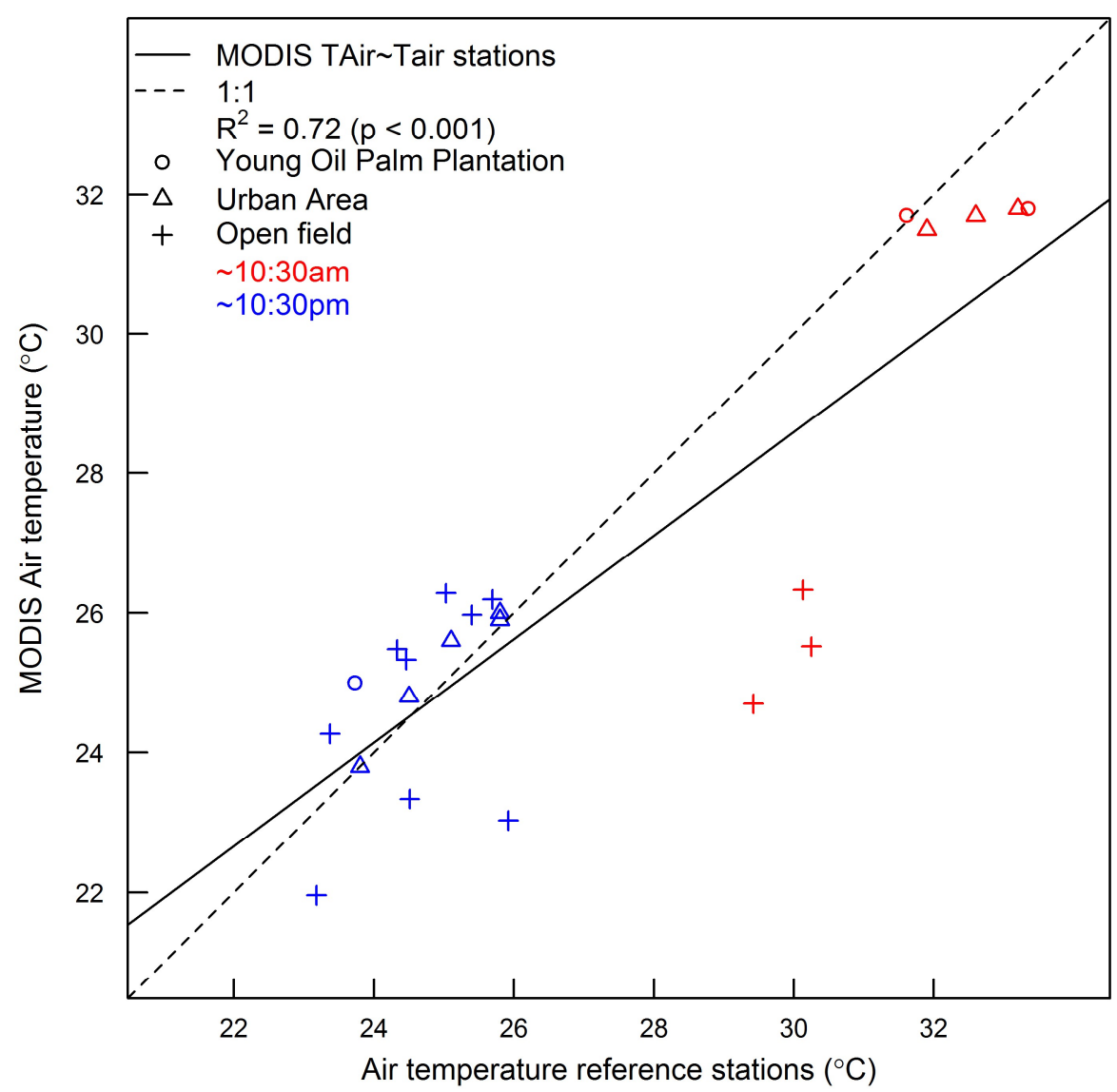

Fig. S8.1 MODIS Air temperature compared with in situ measured air temperatures

Young oil palm plantation (2 years), Urban area and Open field (surrounded by forest) are land use types where the meteorological towers in Jambi were located.

MODIS air temperatures were extracted from the MODIS Air temperature profile product (MOD07) for the three locations.

Both in situ and MODIS observations are consistent, i.e. the morning temperatures (10:30 am, local time) were warmer than the evening temperatures $(10: 30 \mathrm{pm}$, local time). Differences between the two sources are caused by the comparison of point measurements with pixel values, differences in spatial resolution and distance in LST measurements. 
S9. Land use change analysis for the Jambi province for 2000 - 2010

From Clough et al. (2016) we used the observed LULC for a part of the Jambi province.

Table S9.1 Land use change (1990) - 2000-2010

\begin{tabular}{l|rrrrrrr}
\hline & \multicolumn{3}{|c}{ Area $\left.\mathbf{( k m}^{\mathbf{2}}\right)$} & \multicolumn{3}{c}{ Cover (\%) } & \multicolumn{1}{c}{ Change (\%) } \\
\hline LULC & $\mathbf{1 9 9 0}$ & $\mathbf{2 0 0 0}$ & $\mathbf{2 0 1 1}$ & $\mathbf{1 9 9 0}$ & $\mathbf{2 0 0 0}$ & $\mathbf{2 0 1 1}$ & $\mathbf{2 0 1 1 - 2 0 0 0}$ \\
\hline other & 57.83 & 34.34 & 52.41 & 3.3 & 2.0 & 3.0 & 1.03 \\
bush & 84.94 & 263.86 & 346.99 & 4.8 & 15.1 & 19.7 & 4.72 \\
OP & 204.22 & 426.51 & 504.22 & 11.6 & 24.3 & 28.7 & 4.40 \\
RU & 525.90 & 666.87 & 668.67 & 30.0 & 38.0 & 38.1 & 0.06 \\
FO & 881.93 & 361.45 & 182.53 & 50.3 & 20.6 & 10.4 & -10.22 \\
\hline Total & 1754.82 & 1753.03 & 1754.82 & 100 & 100 & 100 & \\
\hline
\end{tabular}

Table S9.2 Contribution of land cover change to total LST increase

\begin{tabular}{l|rrrr}
\hline & Increase 2000 $-\mathbf{2 0 1 0}^{*}$ & $\boldsymbol{\Delta \mathbf { L S T } ^ { * * }}\left({ }^{\circ} \mathbf{C}\right)$ & Contribution to LST $\left({ }^{\circ} \mathbf{C}\right)$ & Remark \\
\hline RU & 0.001 & 0.4 & 0.00 & $1)$ \\
MOP & 0.022 & 0.8 & 0.02 & $2)$ \\
PF & 0.000 & 2.3 & 0.00 & $3)$ \\
YOP & 0.022 & 6.0 & 0.13 & $4)$ \\
UB & 0.005 & 8.5 & 0.04 & $5)$ \\
CLC & 0.029 & 10.9 & 0.31 & $6)$ \\
\hline Total & 0.079 & & 0.51 & \\
Total observed change & 0.102 & & & $7)$ \\
\hline Missing & 0.024 & & &
\end{tabular}

Remarks/explanation:

*) units in fraction of the land cover, which is calculated as the observed change (\%, table S9.1) divided by 100

**) warming effect from Fig. 4a (main text)

1) From the observed changes, but seems to be very underestimated, we assume the remaining rubber is mixed with forests as Jungle Rubber

2) $\mathrm{MOP}=$ we assume half of the plantations to be mature

3) $\mathrm{PF}$ is not included because the area increase is not known

4) $\mathrm{YOP}=$ we assume half of the plantations to be young

5) We assume half of "other" to be urban areas (this assumption is already an overestimation)

6) We assume $50 \%$ of the bush to be degraded areas and barren and $50 \%$ of the class other to be clear cut land

7) $50 \%$ of class "bush" is not included, because this class was not part of our study 


\section{S10. Seasonality analysis}

Overall, the relationships in the dry season are stronger than for the wet season as we have much more usable data during the dry season. We found significant differences between LST of the dry and wet season. At 10:30 am the LST increased $0.09 \pm 0.02{ }^{\circ} \mathrm{C}$ per year during the dry season, while the increase during the wet season was lower $\left(0.06 \pm 0.02{ }^{\circ} \mathrm{C}\right.$ per year) (Fig. $\mathrm{S} 10.1$ ). Around $1: 30 \mathrm{pm}$ the LST increased $0.08 \pm 0.03{ }^{\circ} \mathrm{C}$ per year, against $0.03 \pm 0.02{ }^{\circ} \mathrm{C}$ increase per year during the wet season. At 10:30 pm the LST increased $0.03 \pm 0.01{ }^{\circ} \mathrm{C}$ per year in the dry season, compared to a LST increase of $0.02 \pm 0.01{ }^{\circ} \mathrm{C}$ in the wet season. At 1:30 am, the LST increased $0.05 \pm 0.02{ }^{\circ} \mathrm{C}$ in the dry season, while the LST during the wet season increased $0.05 \pm 0.03{ }^{\circ} \mathrm{C}$. The increase of the LST at $1: 30 \mathrm{pm}, 10: 30 \mathrm{pm}$ and 1:30 am in the wet season was not significant $(\mathrm{p}=0.12, \mathrm{p}=0.06$ and $\mathrm{p}=0.11$, respectively). The significant increase of the LST during the dry season at all 4 times of observations suggests that the warming is more pronounced during the dry season compared to the wet season, which is reasonable as we have more incoming radiation during the dry season. Nevertheless, we prefer to pool the data from the dry and the wet season in order to get more statistically robust relationships.
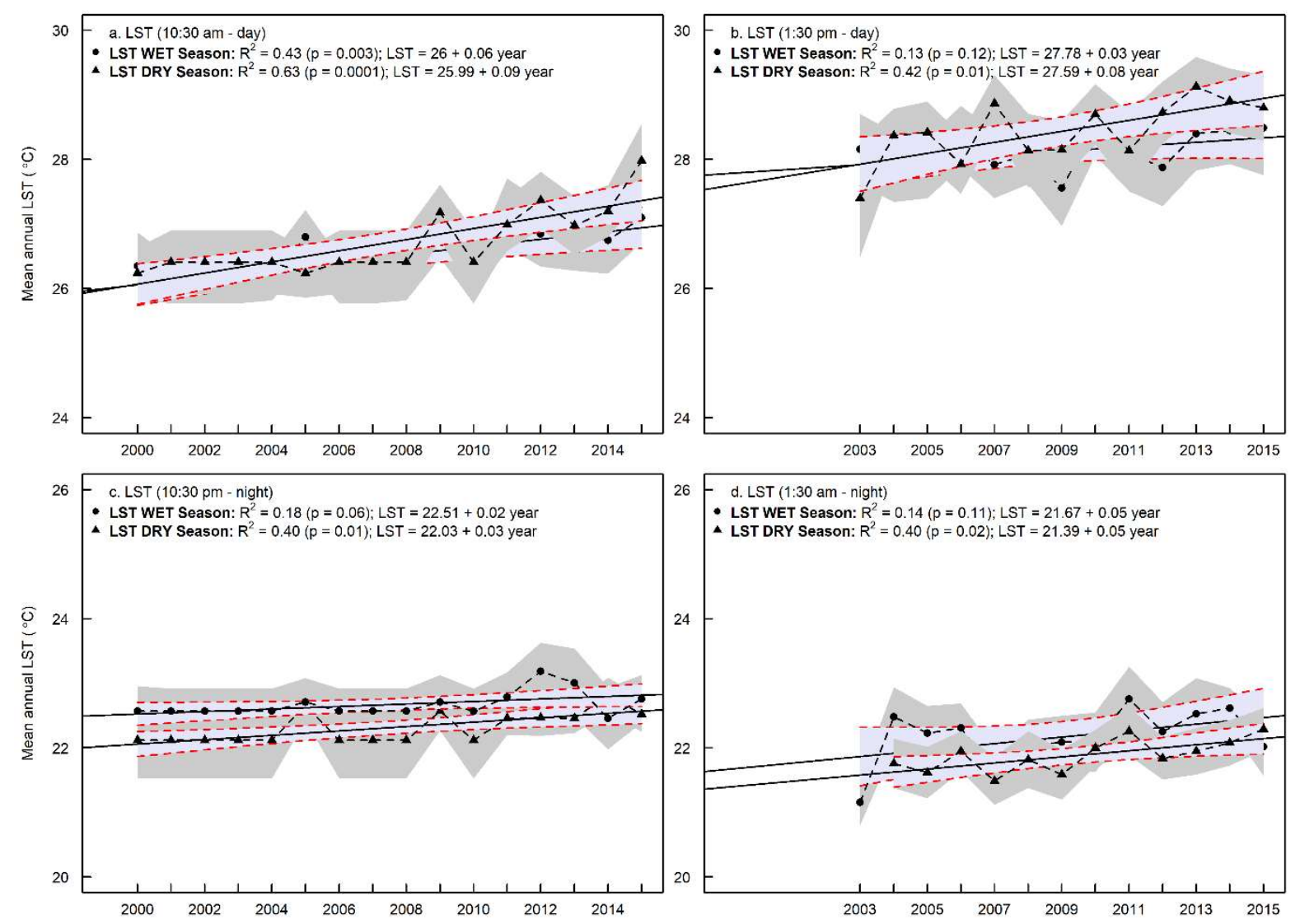

Fig S10.1 Mean annual LST $(\mathrm{a}-\mathrm{d})$, in the Jambi province between 2000 and 2015 derived from MODIS LST (5a. 10:30 am, 5b. 1:30 pm, 5c. 10:30 pm and 5d. 1:30 am, local time) in the wet and dry season.

Grey-shaded areas are the confidence intervals of the means, blue-shaded areas are the confidence intervals of the regression lines. MODIS LST time series for 1:30 pm and 1:30 am were available from the mid of 2002; for this reason we used the complete years from 2003 till 2015. Wet season: All months except June - September/October; Dry season: June September/October. 
In our analysis of the MODIS LST data we have not come across anomalous LST that could be attributed to forest fires. This is caused by the mask we applied in selecting the best quality pixels which probably also removed pixels covered by smoke. A seasonality analysis was not possible with Landsat data because there is not enough data. 


\section{References}

Barsi, J. A., Barker, J. L. and Schott, J. R.: An Atmospheric Correction Parameter Calculator for a Single Thermal Band Earth-Sensing Instrument, Geosci. Remote Sens. Symp. 2003 IGARSS 03 Proc. 2003 IEEE Int., 5, 3014-3016 vol.5, doi:10.1109/IGARSS.2003.1294665, 2003.

Barsi, J. A., Schott, J. R., Palluconi, F. D. and Hook, S. J.: Validation of a web-based atmospheric correction tool for single thermal band instruments, in Proc. SPIE, Earth Observing Systems X, vol. 5882, San Diego, California, USA., 2005.

Bastiaanssen, W. G. M., Menenti, M., Feddes, R. A. and Holtslag, A. A. M.: A remote sensing surface energy balance algorithm for land (SEBAL) - 1. Formulation, J. Hydrol., 212(1-4), 198-212, doi:10.1016/s0022-1694(98)00253-4, 1998a.

Bastiaanssen, W. G. M., Pelgrum, H., Wang, J., Ma, Y., Moreno, J. F., Roerink, G. J. and van der Wal, T.: A remote sensing surface energy balance algorithm for land (SEBAL).: Part 2: Validation, J. Hydrol., 212-213, 213-229, doi:10.1016/S0022-1694(98)00254-6, 1998b.

Bulcock, H. H. and Jewitt, G. P. W.: Spatial mapping of leaf area index using hyperspectral remote sensing for hydrological applications with a particular focus on canopy interception, Hydrol. Earth Syst. Sci., 14(2), 383-392, doi:10.5194/hess-14-383-2010, 2010.

Clough, Y., Krishna, V. V., Corre, M. D., Darras, K., Denmead, L. H., Meijide, A., Moser, S., Musshoff, O., Steinebach, S., Veldkamp, E., Allen, K., Barnes, A. D., Breidenbach, N., Brose, U., Buchori, D., Daniel, R., Finkeldey, R., Harahap, I., Hertel, D., Holtkamp, A. M., Hörandl, E., Irawan, B., Jaya, I. N. S., Jochum, M., Klarner, B., Knohl, A., Kotowska, M. M., Krashevska, V., Kreft, H., Kurniawan, S., Leuschner, C., Maraun, M., Melati, D. N., Opfermann, N., Pérez-Cruzado, C., Prabowo, W. E., Rembold, K., Rizali, A., Rubiana, R., Schneider, D., Tjitrosoedirdjo, S. S., Tjoa, A., Tscharntke, T. and Scheu, S.: Land-use choices follow profitability at the expense of ecological functions in Indonesian smallholder landscapes, Nat. Commun., 7, 13137, 2016.

Coll, C., Galve, J. M., Sanchez, J. M. and Caselles, V.: Validation of Landsat-7/ETM+ ThermalBand Calibration and Atmospheric Correction With Ground-Based Measurements, Geosci. Remote Sens. IEEE Trans. On, 48(1), 547-555, doi:10.1109/TGRS.2009.2024934, 2010.

Huete, A. .: A soil-adjusted vegetation index (SAVI), Remote Sens. Environ., 25(3), 295-309, doi:10.1016/0034-4257(88)90106-X, 1988.

Wukelic, G. E., Gibbons, D. E., Martucci, L. M. and Foote, H. P.: Radiometric calibration of Landsat Thematic Mapper thermal band, Remote Sens. Environ., 28(0), 339-347, doi:10.1016/0034-4257(89)90125-9, 1989. 